\title{
Identidade e processos de identificação: um apanhado teórico
}

Vitor Menezes ${ }^{1}$

\section{Resumo}

Tendo em vista as diferentes formas de abordagem sobre a temática da identidade, assim como os processos de identificação, este trabalho busca apresentar uma análise sobre a perspectiva dos estudos culturais e pós-coloniais sobre o tema. Se mostrando como um dos principais pilares das Ciências Sociais, o discurso sociológico sobre a identidade aponta de que forma a produção de significados e a construção de representações estiveram presentes na vida social individual e coletiva. Com isso, este artigo busca estabelecer um olhar crítico sobre o conceito de identidade, da mesma forma que contribui para um levantamento das diversas interpretações sociológicas no recorte proposto.

Palavras-chave: Identidade; Processos de Identificação; Diferença; Desigualdade.

\begin{abstract}
In view of the different forms of approach about the theme of the identity, as the identification process, this article aims to present an analysis of the perspective of cultural and post-colonial studies about this subject. In showing like one of the mains pillars of the Social Sciences, the sociological discourse about the identity point how the production of meanings and the construction of representations were presents in individual and collective social life. With this, this article aims to establish a critical view about the concept of identity, in the same way that contributes to a collection of the various sociological interpretations.
\end{abstract}

Keywords: Identity; Identification Process; Difference; Inequality.

Recebido em: Agosto, 2013

Aceito em: Junho, 2015

\footnotetext{
${ }^{1}$ Mestrando do Programa de Pós-Graduação em Ciências Sociais da Universidade Federal da Bahia (UFBA) e pesquisador bolsista do projeto Radiografia do Brasil Contemporâneo, do Instituto de Pesquisa Econômica Aplicada (Ipea). Email: vitormatheus_ba@ hotmail.com 
Para citar este artigo:

MENEZES, VITOR; "Identidade e processos de identificação: um apanhado teórico" In: Revista Intratextos, 2014, vol 6, no1, p. 68-81 DOI: http://dx.doi.org/10.12957/intratextos.2014.7106

\section{Introdução}

A criação de representações simbólicas apresenta-se como um dos grandes eixos de discussão das ciências sociais. O processo de identificação, definindo fronteiras internas e externas, individuais e coletivas, é marcado por um contexto relacional e dialógico. Perpassando por diversas esferas da vida social, o tema da identidade é abordado através de diferentes perspectivas e análises. Dessa forma, este trabalho possui o objetivo de realizar um apanhado teórico sobre algumas produções centrais para o entendimento da discussão, em especial no que diz respeito aos estudos culturais e pós-coloniais. Será discutido, primeiramente, um apanhado inicial sobre o tema, a partir do recorte proposto no campo das ciências sociais; posteriormente, serão apresentadas algumas críticas fundamentais à noção de identidade; e por último, o trabalho tratará sobre o tema das fronteiras identitárias.

\section{A Problematização da Identidade pelas Ciências Sociais}

Pensar em identidade, ou identidades, significa refletir sobre os laços intra e extra grupos, o processo de definição de pertencimento e diferença, a produção simbólica e material de fronteiras. Dessa forma, as ciências sociais apresentam a noção de identidade, assim como o processo de identificação, como um dos grandes focos de análise e debate.

Segundo Woodward (2012), a construção da identidade é tanto simbólica quanto social. Isso significa dizer que, estruturada a partir da construção de símbolos, a identidade apresenta-se como um elemento configurador e reconfigurador das práticas sociais. Além disso, a autora destaca que o processo de construção de identidades também vincula-se a causas e consequências materiais. Uma das principais características da identidade é a marcação da diferença, estabelecendo relações de pertencimento, participação, igualdade, mas também de segregação e distanciamento (WOODWARD, 2012). 
Ressalta-se que a discussão sobre a identidade é marcada por uma tensão entre perspectivas essencialistas e não essencialistas. Com isso, para Woodward (2012) a perspectiva essencialista se estabelece a partir da argumentação sobre um processo estático de identidade, trazendo à tona elementos cristalizados, originais, essenciais e autênticos, a serem compartilhados por todos os membros de um grupo identitário, a despeito de transformações dos termos de pertencimento. Segundo a autora, a perspectiva essencialista advém de duas vertentes: a biológica (estabelecida a partir de pressupostos "naturais", por exemplo as características biológicas do corpo que negariam a importância da experiência social) e a histórica ("verdade" estabelecida a partir de um passado único e compartilhado). Em contraste, a perspectiva não essencialista analisa o processo de identificação como um evento dinâmico, sujeito a transformações constantes, destacando a identidade como uma construção social mutável. A representação, através das práticas de significação e os sistemas simbólicos pelos quais os significados são produzidos, constantemente cria e recria posições sociais dos sujeitos.

Prosseguindo com Woordward (2012), vemos que os significados produzidos pelas representações tornam possível a produção de sentidos sobre as nossas experiências e sobre aquilo que somos, estabelecendo identidades individuais e coletivas. A identificação, que ganha destaque com a ênfase na representação e cultura como produtoras de significados, deve ser analisada também como uma relação de poder: o poder de incluir e excluir indivíduos e grupos de papeis sociais situados no sistema de representação, demarcando de forma valorativa as posições dos sujeitos (WOODWARD, 2012). São estabelecidas, dessa forma, críticas a noções originárias de identidade, representando uma essência atemporal e solidificada. Assim, na análise dinâmica e relacional da identificação os diversos sujeitos, individuais e coletivos, estão inseridos em um conjunto de práticas que podem reforçar ou enfraquecer determinados termos de pertencimento e exclusão.

É importante ressaltar, segundo Silva (2012), que a identidade não é o oposto da diferença, ou seja, a inclusão não é o oposto da exclusão. Na verdade, a identidade depende da diferença, são elementos do mesmo processo, definidos através de sistemas classificatórios. A posição dos sujeitos em um sistema de representação também relaciona-se com a divisão material e instrumental da sociedade, em uma relação dialógica entre simbólico e social (SILVA, 2012). Assim, para o autor 
definição - discursiva e linguística - está sujeita a vetores de força, a relações de poder. Elas não são simplesmente definidas; elas são impostas. Elas não convivem harmoniosamente, lado a lado, em um campo sem hierarquias; elas são disputadas [... $\mathrm{Na}$ disputa pela identidade está envolvida uma disputa mais ampla por outros recursos materiais e simbólicos da sociedade (SILVA, 2012, p.81)

É importante destacar que, seguindo a argumentação de Silva, o posicionamento dos sujeitos em um sistema classificatório não é um processo consensual e voluntarista. O campo do sistema simbólico também é um campo de disputas, de discursos, de práticas e ações coletivas. Os fenômenos da inclusão e exclusão em quadros de representação também estão marcados através de relações desiguais, mediadas e disputadas pelos indivíduos e grupos. Vale notar que, para Bauman (1997), na sociedade pós-moderna e de consumo a responsabilidade individual é distribuída igualmente entre todos. No entanto, os meios individualmente possuídos para agir de acordo com essa responsabilidade são atribuídos de forma desigual para os sujeitos. Como o autor ressalta, diferenciam-se os limites de escolhas dos indivíduos e o estoque de recursos necessários para instrumentalizar as decisões (BAUMAN, 1997).

Para Silva (2012), a identidade e a diferença são construções sociais e culturais resultados de atos de criação linguística, sendo que as identidades necessitam ser nomeadas, argumentadas, instituídas por meio de atos de fala. Através da visão pós-estruturalista sobre a representação, descartam-se elementos de conotação mentalista e interioridade psicológica, apresentando a representação como um sistema linguístico e cultural arbitrário e relacionado às relações de poder (SILVA, 2012). Trazendo argumentos de Saussure, o autor aponta que os signos não apresentam valor absoluto, apresentando sentido somente a partir da inserção em uma cadeia infinita de diferentes marcas gráficas e fonéticas. Dessa forma, a relação entre identidade e diferença não se expressa somente como o produto de uma produção simbólica, estando presente também no contexto relacional da linguagem enquanto processo.

Destacando a dinâmica da produção de identidades, Hall (2011) aponta o abalo de quadros de referência que propiciavam ao indivíduo uma posição estável no mundo social. A "crise de identidade" apresenta-se através do deslocamento e fragmentação das identidades modernas, representando a descentração das identidades no mundo social. O rompimento entre a conformidade subjetiva e as necessidades subjetivas da cultura produziu o sujeito pósmoderno, "não tendo uma identidade fixa, essencial ou permanente [...] o sujeito assume identidades diferentes em diferentes momentos, identidades que não são unificadas ao redor 
de um 'eu' coerente" (HALL, 2011, p.13). Diversos processos são responsáveis por essas transformações, ganhando destaque o fenômeno da globalização.

Dessa forma, Hall destaca a tensão entre o local e o global como um problematizador de identidades enraizadas e estabelecidas, assim como a possibilidade da criação de novas identidades "acima" ou "abaixo" do nível nacional. As comunidades imaginadas, originárias, são desconstruídas por um processo de diferenciação e conflito. Como levanta Hall (2011, p.67),

o que, então, está poderosamente deslocando as identidades culturais nacionais, agora, no fim do século XX? A resposta é: um complexo de processos e forças de mudança, que, por conveniência, pode ser sintetizado sob o termo "globalização" [...] desde os anos 70, tanto o alcance quanto o ritmo da integração global aumentaram enormemente, acelerando os fluxos e os laços entre as nações

Desta forma, as identidades, sendo elas individuais, locais ou nacionais, são analisadas não do ponto de vista da unidade interna, mas como dispositivos discursivos exercidos por meio do poder cultural. Como Hall (2011) exemplifica, a raça constitui uma categoria discursiva, não uma categoria biológica, reforçando a ideia do processo de identificação como uma construção situada no terreno das relações de poder, configurando a posição dos indivíduos enquanto sujeitos.

\section{Críticas à noção de identidade}

Além de destacar a identidade como um dos grandes temas das ciências sociais, diversos autores teceram críticas a enquadramentos objetivos e subjetivos dos indivíduos em um sistema simbólico e material. Algumas críticas apontaram argumentos contrários a uma concepção essencialista de identidade, destacando o processo de identificação, ou mesmo indo de encontro à própria noção de identidade. Assim, seguindo a crítica sobre a essencialidade das identidades, Paul Gilroy (2004) vai de encontro às definições de identidade que buscam uma origem comum, distinguindo-se duas categorias: roots (raízes) e routes (rotas), sendo esta última mais apropriada para tratar da problemática identitária. Com isso, Gilroy destaca o processo de identificação como algo relacional, em detrimento de uma noção originária e imaginada da identidade.

Para Bauman, a pós modernidade produz um mundo fragmentado, não sólido, 
profundamente marcado por incertezas. Como argumenta o autor, este mundo "em nossa volta está repartido em fragmentos mal coordenados, enquanto as nossas existências individuais são fatiadas numa sessão de episódios fragilmente conectados” (BAUMAN, 2005, p.18). O pensamento de Bauman opõe-se ao essencialismo, apresentando a construção da identidade como um processo permanente de busca. E ainda assim, esta busca não representa o encontro com algo sólido, mas com algo incerto e ainda não determinado.

Relacionando a construção da identidade com um quebra-cabeça, Bauman aponta que, diferente de um quebra-cabeça comum, a construção da identidade representa a relação entre peças conflitantes e contrastantes. Da mesma forma, o resultado final não é uma imagem pré-estabelecida e coesa, mas um produto desconhecido. Mais do que para os fins, a identificação orienta-se através dos meios (BAUMAN, 2005). A liquidez de que fala Bauman aponta para um processo sem fim, mergulhando o sujeito em um contexto de múltiplas dimensões indeterminadas. O pensamento do autor destaca as consequências da globalização para as identidades locais e nacionais, rompendo com concepções centralizadas e rígidas de identidade a partir de uma problematização sobre relações dinâmicas e complexas, comprimindo o espaço-tempo e recriando formas de pertencimento.

Appiah (2000), por sua vez, destaca os efeitos reais, sociais e psicológicos dos rótulos raciais identitários. Tais rótulos moldam o modo como as pessoas formam suas concepções de si e sobre os seus projetos de vida. Através do processo de identificação, os indivíduos moldam seus projetos para se adequar a uma determinada noção identitária, fazendo uso de conceitos postos à disposição. Ou seja, a relação entre identidade e sujeito não é uma via de mão única, demarcando o indivíduo como participante do processo de identificação. Como aponta Appiah, "in particular, the labels can operate to shape what I want to call 'identification': the process through which an individual intentionally shapes her projects" (APPIAH, 2000, p.608). O autor destaca que o processo de enquadramento identitário não é um processo homogêneo. A construção das noções de identidade nos indivíduos pode se dar de forma adscritiva (através de uma imposição) ou de forma adquirida (através de uma escolha, intencionalidade).

Uma noção de identidade coesa não se dá devido a uma essencialidade. $\mathrm{O}$ rótulo racial funciona apesar da ausência de uma essência, devido aos seus efeitos reais. Como o autor levanta, "if, as I say, you understand the sociohistorical process of construction of the race, you'll see that the label works despite the absence of an essence" (APPIAH, 2000, p.610). Dessa forma, a análise de rótulos raciais torna manifesto como uma construção 
simbólica, desprovida de uma essencialidade, produzindo consequências concretas na sociedade e nas práticas sociais. Para o autor, haveriam limites na política do reconhecimento, já que esta não dá conta da dimensão pessoal da identidade. Assim, ganha realce conflitos potenciais entre as políticas de identidade e as liberdades individuais, perspectiva que será contraposta por outras abordagens trabalhadas a seguir.

Problematizando a noção de identidade, Nancy Fraser $(2002,2007)$ estabelece uma análise a partir do campo de discussão da justiça social, buscando superar a oposição entre reconhecimento e redistribuição através de um viés binomial de justiça. Se do ponto de vista da redistribuição a injustiça surge a partir da desigualdade material, do ponto de vista do reconhecimento a injustiça surge na forma da subordinação de estatuto. A solução, nesse caso, deve ir muito além das políticas de identidade, abarcando os esforços de reconhecimento e valorização da diversidade, por um lado, e, por outro, os esforços de transformação da ordem simbólica e de desconstrução dos termos em que são construídas as diferenciações de estatutos existentes (FRASER, 2002). O reconhecimento, dessa forma, não ocasionaria uma política restrita a um determinado grupo, mas uma transformação de um estatuto social.

O resolvimento do binômio reconhecimento-redistribuição se dá a partir da paridade de participação, através da transformação do estatuto social, possibilitando a participação na vida social a todos enquanto membros plenos da sociedade. O reconhecimento é estabelecido como uma reivindicação de justiça, centrada em uma noção ampla. Com isso, Fraser critica a noção de identidade, já que esta termina por reificar a cultura e valorizar a estrutura psíquica em detrimento de instituições e normas sociais. Como fala a autora, "o que exige reconhecimento não é a identidade específica de um grupo, mas as condições dos membros do grupo como parceiros integrais na interação social” (FRASER, 2007, p.106). Substitui-se, assim, o modelo de identidade pelo modelo alternativo de estatuto social.

Propondo um profícuo debate, Judith Butler critica a perspectiva presente em Fraser de que certos movimentos estariam situados na esfera da economia política, sendo outros movimentos (como relativos ao gênero e sexualidade) caracterizados como "meramente culturais”. Pra Butler (1998), a divisão sexual do trabalho não pode ser compreendida separadamente da reprodução de categorias estabelecidas de gênero, sendo que a regulação da sexualidade está articulada ao modo de produção adequado à economia política. Assim, 
struggles to transform the social field of sexuality do not become central to political economy to the extent that they can be directly tied to questions of unpaid and exploited labor, but rather because they cannot be understood without an expansion of the "economic" sphere itself to include both the reproduction of goods as well as the social reproduction of persons" (BUTLER, 1998, p.40)

Também por uma perspectiva contrária ao pensamento de Fraser, Young (2009) coloca-se de encontro à existência de distinção entre processos materiais da economia política e processos simbólicos da cultura. Para a autora, "Fraser exagera o grau em que uma política de reconhecimento se afasta das lutas econômicas" (YOUNG, 2009, p.194), havendo pouca evidência para a argumentação de que os movimentos ditos "de reconhecimento" ignorariam questões relativas à desvantagem econômica, com especial atenção para o ativismo feminista e antirracista. Propondo um contraponto à oposição colocada por Fraser entre ação afirmativa e ação transformadora, Young (2009, p.195) destaca:

\footnotetext{
$\mathrm{Na}$ proporção em que existem tendências para uma política de reconhecimento visando suplantar as preocupações com a justiça econômica, Fraser está certa em criticá-las. Mas o remédio por ela proposto, o de reafirmar uma categoria de economia política inteiramente oposta à de cultura, é pior do que a doença. Sua dicotomia entre economia política e cultura leva-a a distorcer o sentido dos movimentos feminista, antirracista e de liberação dos homossexuais, entendendo-os como movimentos que reivindicam o reconhecimento como um fim em si mesmo, quando eles são mais bem compreendidos como movimentos que concebem o reconhecimento cultural como um meio para alcançar justiça econômica e política.
}

Em réplica, Fraser argumenta que a dicotomia contraposta por Young não surgiu de um ato de imaginação, mas sim do diagnóstico da existência dissociada entre cultura e economia política como um produto histórico da cultura política pós-socialista (FRASER, 2009). Assim, ao invés de reificar essa dicotomia, Fraser (2009, p.216) defende a proposição de transcendência dessas divisões, distinguindo correntes afirmativas de correntes transformativas no interior dos movimentos, "com vistas a mostrar como as demandas por redistribuição e por reconhecimento poderiam ser mutuamente integradas em um projeto político compreensivo".

Prosseguindo com o debate, a autora afirma que seu trabalho não partiu da percepção de que os processos materiais da economia política e os processos simbólicos da cultura 
seriam em si opostos, mas sim da apreensão crítica de que o capitalismo diferenciou arenas e instituições econômicas de arenas e instituições culturais, sendo necessário "considerar tanto o fato histórico da diferenciação capitalista entre o econômico e o cultural como a realidade subjacente de sua completa interpenetração" (FRASER, 2009, p.217). Por fim, Fraser (2009, p.218) argumenta:

\footnotetext{
Refutando a visão de que cultura e economia constituem duas esferas separadas e mutuamente isoladas, revelei sua interpenetração, investigando os efeitos nãointencionais das demandas culturais e econômicas. O propósito essencial de meu ensaio foi demonstrar que reivindicações culturais têm implicações distributivas, que demandas econômicas incluem subtextos de reconhecimento, e que corremos o risco de ignorar sua influência recíproca.
}

Após essa trajetória bibliográfica, mostra-se necessário ressaltar que as diferentes perspectivas de análise defendem que os problemas identitários são muito mais complexos do que um enquadramento rígido baseado em um modelo originário de identidade. Relacionamse elementos simbólicos com elementos materiais, assim como os sujeitos são vistos como elementos atuantes e transformadores de um processo de identificação dinâmico e relacional.

\section{As fronteiras identitárias}

As fronteiras ("boundaries") delimitam a separação das pessoas em grupos. Ao mesmo tempo que definem quem está "fora", também definem quem está "dentro", gerando sentimentos de similaridade e de filiação. As diferenças e similaridades, além de serem definidas e pensadas, são também performadas pelos indivíduos, sendo as fronteiras um meio essencial para a disputa por status e monopolização de recursos. É importante destacar que as fronteiras não definem somente campos opostos e polarizados, também produzindo formas híbridas e novas vias de categorização.

Como argumenta Lamont e Virag (2002), as fronteiras manifestam o processo fundamental da relacionalidade, através da construção de grupos como similares ou diferentes, moldando o entendimento dos atores sociais sobre as responsabilidades e ações. Segundo os autores, é necessário analisar as fronteiras propriamente ditas, problematizando os fenômenos de construção das fronteiras, suas redefinições e cruzamentos, etc. Dessa forma, 
focusing on boundaries themselves may generate new theoretical in- sights about a whole range of general social processes present across a wide variety of apparently unrelated phenomena - processes such as boundary-work, boundary crossing, boundaries shifting, and the territorialization, politization, relocation and institutionalization of boundaries (LAMONT; VIRAG, 2002, p.168)

A Sociologia Cultural assume como foco o processo em que as fronteiras são construídas e moldadas pelo contexto, em particular pelas categorias culturais, tradições e narrativas individuais. Assim, as fronteiras não são criadas por indivíduos atomizados, mas pela relação entre os indivíduos circunscritos em uma ambiente social. As definições institucionalizadas de pertencimento cultural moldam as fronteiras do "self" e do grupo (LAMONT; VIRAG, 2002). Lamont e Virag (2002) também definem a distinção entre fronteiras sociais e simbólicas, sendo as fronteiras simbólicas ferramentas que tornam possível o debate sobre definições de realidade, através de distinções conceituais feitas pelos atores sociais. Os sistemas e princípios de classificação se dão em um terreno de disputa, pela profusão e difusão das categorias.

Por sua vez, as fronteiras sociais são formas objetivadas de diferenças sociais, através do acesso desigual a oportunidades e a recursos materiais e imateriais. Lamont e Virag (2002) destacam que as fronteiras sociais e simbólicas são fenômenos igualmente reais. Enquanto as fronteiras sociais se manifestam através da associação entre indivíduos, as fronteiras simbólicas se manifestam no nível da intersubjetividade. A distinção entre as fronteiras não deve significar a separação rígida e estática entre ambas, mas sim um complexo e dinâmico sistema relacional, na qual fronteiras sociais e simbólicas se interferem, se transformam e se reconfiguram (LAMONT; VIRAG, 2002).

Ganha destaque que os sentidos sobre o pertencimento e a exclusão podem ser entendidos somente dentro dos sistemas de significação. No entanto, isso não significa dizer que eles são fixos e imutáveis, sendo a linguagem (central para o processo de representação) uma estrutura instável e sujeita à transformações (SILVA, 2012). Como argumenta Silva (2012, p.80), “a identidade e a diferença são tão indeterminadas e instáveis quanto a linguagem da qual dependem". A indeterminação também circunscreve a atribuição de sentidos ao mundo social como um terreno de disputa em torno desta atribuição. Transpondo a limitação do discurso sobre as identidades como a necessidade da tolerância e do respeito, Silva chama atenção para a necessidade de questionar como a identidade e a diferença são ativamente produzidas através de relações de poder. 
Por sua vez, Jeffrey Alexander (2007) distingue, na definição sobre as desigualdades, a diferença entre um modelo "forte" e um modelo "fraco" de Sociologia Cultural. Enquanto abordagens mais tradicionais descartavam o elemento cultural, sendo a desigualdade um produto da esfera econômica, o modelo fraco da Sociologia Cultural insere o elemento cultural subordinado à esfera econômica. Dessa forma, existiria uma hierarquia entre a economia e cultura, sendo a cultura subordinada à economia simplesmente como um elemento adicional decorrente de uma estrutura sólida em bases materiais. A luta contra a desigualdade, pois, não passava por disputas culturais (ALEXANDER, 2007). Já o "modelo forte" de Sociologia Cultural proposto pelo autor evidencia a cultura como um elemento central na realidade social, não subordinada a qualquer outro fator. Em contraste ao que ele chama de um modelo reducionista e vertical, Alexander (2007) propõe um modelo simbólico e a horizontal, em que a imposição da desigualdade, e as disputas por justiça, inclusão e distribuição são mediatizadas culturalmente.

Como salienta Alexander (2007), um sistema desigual expressa fenômenos de exclusão e distribuição injusta que são mediadas pela cultura. A criação e manutenção da desigualdade estão intimamente ligadas a uma construção de significado, inserida em um sistema de significação. Questionar a construção dos significados e a mediação cultural dos termos em que são inscritos a desigualdade se mostra como uma ofensiva ao próprio sistema econômico, político e social. Assim, o autor aponta para o caráter ativo dos atores, inserindo a cultura na esfera política de disputa. A relativa autonomia da sociedade civil resulta no caráter fundamentalmente contestável e instável de toda forma de dominação e distribuição desigual. (ALEXANDER, 2007). Um sistema de categorias das fronteiras simbólicas é essencial para a legitimação de desigualdades, o que acarreta no fato de que a contestação cultural destas fronteiras é um fenômeno essencial para a superação da injustiça.

Apresentando uma importante contribuição à teoria pós-colonial, Avtar Brah (2006) afirma que "toda formação discursiva é um lugar de poder", estando o poder constituído de forma performática por meio de práticas econômicas, políticas e culturais. A autora propõe, dessa forma, uma problematização sobre a diferença a partir de quatro eixos analíticos: a experiência, a relação social, a subjetividade e a identidade. Inicialmente, Brah defende uma perspectiva contrária ao "sujeito da experiência" (constituído previamente, onde as experiências simplesmente "acontecem”), sendo a experiência o lugar de formação do sujeito. Nesse processo, “o 'eu' e o 'nós' que agem não desaparecem, mas o que desaparece é a noção de que essas categorias são entidades unificadas, fixas e já existentes, e não modalidades de 
múltipla localidade, continuamente marcadas por práticas culturais e políticas cotidianas" (BRAH, 2006, p.361).

Em seguida, a diferença como relação social é apreendida a partir das trajetórias históricas e contemporâneas relacionadas aos contextos materiais e de práticas culturais que propiciam as condições para a produção das identidades de grupo. Por sua vez, a subjetividade, sendo entendida como "o lugar do processo de dar sentido a nossas relações com o mundo", consiste na forma em que o sujeito-em-processo experimenta a identidade a partir de seus caracteres contraditórios (BRAH, 2006, p.371). Por fim, para Brah (2006, p. 371) a identidade coletiva "é o processo de significação pelo qual experiências comuns em torno de eixos específicos de diferenciação - classe, casta ou religião - são investidas de significados particulares".

\section{Conclusão}

A identidade, ou as identidades, são um dos grandes pilares da sociologia compreensiva. A sua importância expressa também as diversas formas de enxergar o fenômeno, relacionando-se a isto a produção intelectual dos autores e o contexto histórico e social no qual o conhecimento é produzido. Os diversos termos em que se dá a inclusãoexclusão dos indivíduos, assim como o posicionamento dos sujeitos individuais e coletivos em distintas esferas de poder, são problematizados pelas ciências sociais como relações sociais inseridas em um contexto desigual de possibilidades e oportunidades.

Enxergar os indivíduos enquanto sujeitos participantes do processo de identificação resulta em uma crítica ao modelo de identidade como uma via de mão única, no qual a identidade estática é simplesmente aceita por indivíduos ou grupos. Ressalta-se aqui a defesa da identidade como processo dialógico e dinâmico, assegurando o espaço das práticas sociais na compreensão dos processos de identificação.

Dessa forma, o processo de identificação, rompendo com uma visão essencialista, originária e estática da identidade, destaca as características dinâmicas e mutáveis das fronteiras simbólicas. Fronteiras estas que apontam para os sujeitos como parte integrante e atuante, como um elemento capaz de manter ou transformar. A sociologia, dessa forma, oferece instrumentos importantes para situar o debate da identidade no contexto atual, sendo que a chamada crise das identidades revela, assim, uma reconfiguração das formas de pertencimento dos indivíduos e grupos, complexificando o tema da identidade, seja ela individual, local ou nacional, em um contexto transnacional marcado pela desigualdade. 


\section{Referências Bibliográficas}

ALEXANDER, Jeffrey C. The Meaningful Construction of Inequality and the Struggles Against It: A 'Strong Program' Approach to How Social Boundaries Change. Cultural Sociology. Los Angeles, London, New Delhi and Singapore: BSA Publications Ltd SAGE Publications. Volume 1(1): 23-30 2007.

APPIAH, K. Racial Identity and Racial Identification. In Back, L.; SOLOMOS, J. (eds.). Theories of Race and Racism. A reader. London/New York: Routledge, 2000, pp.606-615.

BAUMAN, Zygmnt. Identidade. Rio de Janeiro: Zahar, 2005. Sobre o Comunitarismo e a Liberdade Humana, ou Como Enquadrar o Círculo. In: O Mal Estar na Pós Modernidade. Rio de Janeiro: Zahar, 1998.

BRAH, Avtar. Diferença, diversidade, diferenciação. Cadernos Pagu (26), janeiro-junho de 2006: pp.329-376.

BUTLER, Judith. Merely Cultural. New Left Review. Jan 1, 1998.

FRASER, Nancy. Justiça Social na Globalização: redistribuição, reconhecimento e participação. Revista Crítica de Ciências Sociais, 63, Outubro 2002: 7-20

Reconhecimento Sem Ética? Lua Nova, São Paulo, 70: 101-138, 2007.

Uma réplica a Iris Young. Revista Brasileira de Ciência Política, $n^{\circ} 2$. Brasília, julho-dezembro de 2009, pp. 215-221.

GILROY, Paul. Identity, Belonging, and The Critique of Pure Sameness. In: Between Camps. Nations, Cultures and the Allure of Race. London: Routhledge, 2004 [2000].

HALL, Stuart. A Identidade Cultural na Pós-Modernidade. Rio de Janeiro: DP\&A, 2005 LAMONT, Michèle; MOLNAR, Virag. The Study of Boundaries in the Social Sciences. 
Annu. Rev. Sociol. 2002. 28:167-95.

SILVA, Tomaz Tadeu da (org). Identidade e diferença: A perspectiva dos Estudos Culturais. Petrópolis: Vozes, 2000.

YOUNG, Iris Marion. Categorias desajustadas: Uma crítica à teoria dual de sistemas de Nancy Fraser. Revista Brasileira de Ciência Política, nº 2. Brasília, julho-dezembro de 2009, pp. $193-214$ 